\title{
Improving the School Quality Through Winning Education Turbulence in Uzbekistan (Evidence from the Ministry of Secondary Education Uzbekistan, Gijduvan Region 65 Schools)
}

\author{
Aziz Zikriyoev, Sokhibmalik Khomidov, Ravshan Nurimbetov, Tokhir Khasanov, Zebo \\ Abdullayeva
}

\begin{abstract}
This research discusses current status of secondary education quality and prospective development outcomes from the testable research area in 65 school quality parameters of Gijduvan district Bukhara region in Uzbekistan. The authors try to discover the problem in which relating improvement of education system at schools far from the capital. By sorting out 60 variables authors come across final decision and demonstrate the feasibility of economic and social effectiveness of each school. Current article opens up a new field in preconditions, causes and consequences of influenced education quality variables in which selected secondary schools. Authors excluded 10 variables from the research analyses of major schools due to collected data are the same results. Specific area of interest in cases of Gijduvan are distributed and analyzed in Eviews 9.0. Perhaps, paper work offers a solution for the of relationship of school quality by winning turbulence education via empirical analyses. Main findings have been distributed in forms of the least square method. An objectivity of discussion is concentrating on turbulence trajectory as a total loses of quality at schools and winning it's directions by conceptual figure which offered by authors. The authors also made an attempt to provide reasons for raising visibility of schools through quality education by calculating efficiency in three ways. Finally, conclusion of paper suggests that each selected variable efficiency calculated in detail coefficients and presented marble model of obtained results for testing secondary school quality of other regions in Uzbekistan.
\end{abstract}

Keywords: Gijduvan, secondary education, education quality, turbulence education, pupil, reforms.

\section{INTRODUCTION}

School quality is always indicated by levels of student achievement or by school ranking which are related to student performance at classes. Instead, government investment strategies should focus on school efficiency which influences student achievement, shaping of talents

Revised Manuscript Received on 14, October 2019.

Aziz Zikriyoev, Teacher at Department of World Economy at Tashkent State University of Economics, ORCID, Uzbekistan(Email: a.zikriyoev@tsue.uz)

Sokhibmalik Khomidov, PhD, Department at Econometrics at Tashkent State University of Economics, Uzbekistan(Email: soxibmalik1981@mail.ru)

Ravshan Nurimbetov, DSc, Vise-Rector at Research and Innovation at Architecture and Civil Engineering Institute Tashkent, Uzbekistan(Email: r.i.nurimbetov@bk.ru)

Tokhir Khasanov, PhD, Senior Lecturer at the Academy of Public Administration under the President of the Republic of Uzbekistan, Uzbekistan(Email: tohirh@yahoo.fr)

Zebo Abdullayeva, Head of Secondary Education Department in Gijduvan Region, Uzbekistan(Email: gishtimir@yahoo.com) and efforts which support innovative education system inputs by local and international school staff.

The impact of school quality on student achievement has been heavily debated since the publication of the Coleman Report, which found relatively small effects of differences in the measured attributes of schools on student outcomes (Coleman et al. (1966)). On the one hand, the importance attached to school choice and resources invested by parents and policy makers in schools suggests school quality plays an important role in child development. This is supported by evidence of the importance of good teachers (e.g. Rockoff (2004); Rivkin et al. (2005); Jackson (2013); Chetty et al. (2014)) and school level comparisons using quasi-random variation in school assignment which show significant effects on student outcomes (e.g. Hastings and Weinstein (2007); Pop-Eleches and Urquiola (2013)). On the other hand, several similar school-level studies fail tofind an impact on student achievement (e.g. Clark (2010); Cullen et al. (2005)). The evidence from the vast literature analyzing the effect of school quality using measures such as class size, teacher characteristics, or expenditure per capita on student outcomes is also mixed. Consequently, the fact that the past literature does not consistently detect a significant impact of school quality may not be due to the absence of a relation between school quality and student outcomes. Understanding the role of school quality in determining student achievement is important given the significant returns to better test scores (e.g. school attainment: Currie and Thomas (1999); Murnane et al. (2000) and wages:

Murnane et al. (1995)). It is also important to account for the role of school quality to avoid bias in studies of skill formation (e.g. Cunha and Heckman (2008); Cunha et al. (2010); Todd and Wolpin (2003)). For example, ignoring the role of school quality is likely to lead to overestimates of the own-productivity of skills.

Rather than being seen as exceptions to the rule that schools cannot change, the development of a small number of innovative practices and schools may instead reflect the rule that schools can only change through the monumental effort, unusual resourceful-ness, and strong leadership of key individuals or groups.

Published By:

Blue Eyes Intelligence Engineering \& Sciences Publication 


\section{IMPROVING THE SCHOOL QUALITY THROUGH WINNING EDUCATION TURBULENCE IN UZBEKISTAN (EVIDENCE FROM THE MINISTRY OF SECONDARY EDUCATION UZBEKISTAN, GIJDUVAN REGION 65 SCHOOLS)}

(Hatch, 2000)

Many previous studies have analyzed the effect of school quality using measures such as class size, teacher characteristics, or expenditure per capita to infer their impact on student outcomes (e.g. Angrist and Lavy (1999); Chetty et al. (2011); Dynarski et al. (2013); Goldhaber and Brewer, (2000); Hanushek (1997); Rivkin et al. (2005)). These studies consider these variables to be direct inputs in the achievement production function. Since it assumes a direct causal relationship between the input variables and outcomes, this approach does not need the concept of school quality. While some of these studies find a significant effect, others do not (see e.g. Hanushek (2003) for an overview). We argue that the failure to detect an impact is not due to the absence of a relation between school quality and student outcomes, but that a positive and significant relationship is detected when these variables are fewer effective measures of school quality.

Turbulence Theory Started with the study of innovation in schools: (Gross 1998) school innovated, there always seemed to be a level of disturbance. Schools seemed to experience different levels of disturbance, Schools exhibited different responses to disturbance, each of these were anomalies, not accounted for in linear models of innovation. Similar to Kuhn's work (1962) regarding scientific revolutions.

"It is important to understand the relative situation of individuals in the organization in a multi-dimensional fashion. In the case of educational institutions this means not only attempting to be empathetic to the turbulence as students might experience it...but also acknowledging that groups of students (by gender, race, age, SES, or years in the community) may experience it differently. Equally, it means seeing individuals... as separate beings. This is not a linear, easily nested process." (Shapiro and Gross 2007) An innovating school deals with cascading as a positive feedback loop an urban elementary does well with its startup reform (Gross 2004).

A gifted leader stabilizes his innovative high school during severe turbulence with dialogue a commitment to continuous communication; democracy-equality and shared power; innovation-invention and refinement to promote the mission (Gross 2001).

Positionality, Cascading, and Stability ignite at one reforming school leading to Extreme Turbulence. The supporting superintendent leaves, foundation funding runs out, two additional grade levels are added, new staff comes who do not subscribe to the reform plan, new families are assigned to the school who do not believe in the reform effort, one grade level fails the high stakes test, the founding principal plans to retire asap. (Gross 2002).

Rather than being seen as exceptions to the rule that schools cannot change, the development of a small number of innovative practices and schools may instead reflect the rule that schools can only change through the monumental effort, unusual resourcefulness, and strong leadership of key individuals or groups. (Hatch, 2000).

\section{METHODOLOGY}

Research Philosophy: In this research we used survey method by giving 60 questions to all 65 secondary schools of Gijduvan district Bukhara region in Uzbekistan. It determines the way a specific set of data has been collected, inferred and utilized for a research work. All collected data distributed in positivism, realism and interpretivism.

Research Approach: From the modern tendencies of the world education system can be seen that innovations via transfer technology and interpreting big data. Integration of secondary education system of Uzbekistan has already become more competitive. By transforming secondary schools teaching system into global education methodology increasing visibility of schools in various aspects among world class schools in Uzbekistan. As for the analyses we tested deductive approach based on current research.

Research Strategies: In accordance with the research survey questions collected primary source of data is qualitative. In spite of the collected date was from the different geographical locations of school results and outcome can be reached main objectivity of the research.

Time Horizon: Current research work has been conducted in panel data analysis with regression and correlation of chosen variables by determining variation ecoefficiency. All data analyzed in Eviews 9.0 software with econometrics modeling and tested in Housman method ( $F$ test and $\chi 2$ test).

Data Collection: For collecting data we learned each 65 schools on topic "Improving school quality". All schools have been agreed research project in current topic and for data would prefer using descriptive survey method to prove validity and reliability of the collected data set. Survey questions organized in closed and liker scale formats.

\section{PURPOSE}

1. This paper will review the research conducted on identify current academic achievements of the selected schools.

2. This paper will describe discussion on statistical and mathematical analyzing collected data by comparing the priority results with each selected school.

3.This report will explain how raising school quality by enhancing comprehensive visibility of schools by wining Turbulence Education in Uzbekistan.

\section{RESULTS}

Collected data analyzed in panel data, and the panel units were schools in Gijduvan district of Bukhara region. The data from each school cross section are shown as panel units. While econometric analyzes of variables such as education efficiency (educ_effec), classroom size (area_room), and other variables were considered as arbitrary variables, educational efficiency (educ_effec) was chosen as the most appropriate variable for research purposes. To explain this logically, all changes in a particular school will eventually have an impact on the effectiveness of education. Of course, the impact of other factors in economic analysis also influences the effectiveness of education. However, their importance is negligible. The following steps were performed in the study 
to calculate the panel models described above.

Firstly, choosing a free variable. In the regression model, the independent variables were chosen based on the theory. At the same time, it is necessary to take into account the correlation of some variables. In cases where the correlation coefficient between the two regressors is high (although there is no multicollinearity problem), the high correlation coefficient increases the standard error in calculating the econometric model. One of the variables with the highest correlation was chosen when selecting variables for the model. Although the normal correlation coefficient does not take into account intervals or panel correlations separately, it represents the link between the two variables under consideration.

Secondly, arbitrary and volatile variables vary between panel units and time. The inter-variable variation is termed inter-variation, and the variance between schools is called the variation between panel units, calculated as follows:

Intermediate dispersion:

$$
\begin{aligned}
s_{\text {within }}^{2}=\frac{1}{N T-1} & \sum_{i} \sum_{t}\left(x_{i t}-\bar{x}_{i}\right)^{2} \\
& =\frac{1}{N T-1} \sum_{i} \sum_{t}\left(x_{i t}-\bar{x}_{i}+\check{x}\right)^{2}
\end{aligned}
$$

Dispersion between panel units:

$$
s_{\text {between }}^{2}=\frac{1}{N T-1} \sum_{i} \sum_{t}\left(x_{i t}-\bar{x}_{i}\right)^{2}
$$

General dispersion:

$$
s_{\text {total }}^{2}=\frac{1}{N T-1} \sum_{i}\left(x_{i t}-\bar{x}_{i}\right)^{2}
$$

It is desirable to distinguish between time intervals and panel units for calculation using panel models. In particular, when calculating the model of fixed effects, the interval variation is less effective than the variation between panel units, which produces ineffective estimates.
Thirdly, the base model as a base model is estimated using the least square method. Although it is not appropriate to calculate panel sampling using the least square method.

In addition, the complex error in calculating the model $\boldsymbol{y}_{i t}=\boldsymbol{x}_{i t} \boldsymbol{\beta}+\mathbf{z}_{i} \boldsymbol{\alpha}+\boldsymbol{\varepsilon}_{i t}$ using the least square is a prerequisite for testing hypotheses. This hypothesis is not satisfied with panel data and therefore is not effective even though the calculated parameters are valid. Furthermore, the computation error of the $\varepsilon_{\mathrm{it}} \sim(0, \sigma \varepsilon)$ model with the least square method is a prerequisite for testing hypotheses. This hypothesis is not satisfied with panel data and therefore is not effective, although the calculated parameters are reasonable. In this case we selected eight parameters among sixty which is close to our analyze area. And they are coded as followings:

1. educ_effec...............education effectiveness

2. area_classroom.........area of the classroom per pupil

3. distance_center.........distance of the schools from center

4. number teachers......number of teachers at each school

5. masters_degree.........number of master degree teachers at school

6. conference_pupils......attendance of pupils at conferences and workshops

7. learning_foreign language.... foreign language proficiency

8. teachers_using innovation website.... regularly using website of the ministry of innovation

9. training_qualific......participation at trainings and achievements of qualification in certain area of teachers

Table 1

Results of calculating panel model parameters $y_{i t}=x_{i t} \beta+z_{i} \alpha+\varepsilon_{i t}$

\begin{tabular}{|l|l|l|l|l|}
\hline & $(\mathbf{1})$ & $\mathbf{( 2 )}$ & $\mathbf{( 3 )}$ & $\mathbf{( 4 )}$ \\
\hline $\begin{array}{l}\text { Custom variable: } \\
\text { educ_effec }\end{array}$ & Model of assembly & $\begin{array}{l}\text { Cluster-resistant } \\
\text { aggregate model }\end{array}$ & Immutable effects & Random effects \\
\hline area_classroom & $0.496^{* * *}$ & 0.496 & $0.734 * * *$ & $0.761^{* * *}$ \\
\hline & $(0.0822)$ & $(0.355)$ & $(0.218)$ & $(0.0925)$ \\
\hline distance_center & $0.536^{* * *}$ & 0.536 & 0.034 & 0.292 \\
\hline & $(0.0931)$ & $(0.465)$ & $(0.419)$ & $(0.0824)$ \\
\hline number_teachers & $0.458^{* * *}$ & 0.458 & 0.789 & $0.785^{*}$ \\
\hline & $(0.0722)$ & $(0.543)$ & $(0.781)$ & $(0.0814)$ \\
\hline masters_degree & $0.729^{* *}$ & 0.729 & $0.331^{*}$ & $0.299^{* *}$ \\
\hline & $(0.0511)$ & $(0.645)$ & $(0.149)$ & $(0.0614)$ \\
\hline conference_pupils & $0.618^{* * *}$ & 0.617 & $0.232^{*}$ & $0.189 * *$ \\
\hline $\begin{array}{l}\text { learning_foreign } \\
\text { language }\end{array}$ & $(0.0412)$ & $(0.465)$ & $(0.259)$ & $(0.0314)$ \\
\hline & $0.728^{* * *}$ & 0.429 & $0.464 *$ & $0.278^{* *}$ \\
\hline $\begin{array}{l}\text { teachers_using } \\
\text { innovation website }\end{array}$ & $(0.0931)$ & $(0.465)$ & $(0.419)$ & $(0.0824)$ \\
\hline training_qualific & $0.736^{* * *}$ & 0.556 & 0.064 & 0.892 \\
\hline Average & $(0.0722)$ & 0.832 & $0.115^{*}$ & $0.263^{* *}$ \\
\hline
\end{tabular}

Standart errors in parametrs $* * * \mathbf{p}<0.01, * * \mathbf{p}<0.05$, $\mathbf{p}<0.1$

Fourth, although there are several empirical computational methods based on panel data, the most 


\section{IMPROVING THE SCHOOL QUALITY THROUGH WINNING EDUCATION TURBULENCE IN UZBEKISTAN (EVIDENCE FROM THE MINISTRY OF SECONDARY EDUCATION UZBEKISTAN, GIJDUVAN REGION 65 SCHOOLS)}

common are nonlinear effects (OLS) and random effects (GLS - Generalized least squares, MLE - Maximum likelohood estimation). In this case, it is advisable to use a fixed effects model if there are unobservable interim variables that affect educational performance and variable effects between panel units are strong.

Fifth, we use the Hausmann test to choose one of the fixed and random effects models. According to this test, $\theta 1$ is known to be $\theta 2$ and is assumed to be effective.

H0: $\theta 2$ evaluation $\theta 2$ is an effective estimate of the true parameter $\theta 2$. If the null hypothesis is true, there is no systematic difference between these two estimates, and the random effects model is used to calculate regression parameters. If the null hypothesis is not true, there is a systematic difference between the two estimates, and the parameters calculated using random effects are rejected, and the parameters calculated using the unchanged effects model are valid.

Summary models (Models 1, 2) In the first computational model computed in Eviews 9.0 using the least square method, variables such as distance_cent, number_teachers, learning_foreign language have a $1 \%$ statistical significance. Their quantitative growth and other factors have led to an increase in the effectiveness of school education under the same conditions.
1. Compact models and caster-mounted assembly models:

educ_effec $=6.523+0.496 \cdot$ area_room +0.536 . distance_cent $+0.458 \cdot$ number_teachers +0.799 . masters_degree $+0.618 \cdot$ conference_pupils +0.728 . learning_foreign language $+0.736 \cdot$ teachers_us in innovation website $+0,785 \cdot$ training_qualific

\section{Interaction Model:}

educ_effec $=2.412+0.734 \cdot$ area_room +0.034 . distance_cent $+0.789 \cdot$ number_teachers +0.331 . masters_degree $+0.232 \cdot$ conference_pupils +0.464 . learning_foreign language $+0.064 \cdot$ teachers_us in innovation website $+0,8324 \cdot$ training_qualific

\section{Random effects model:}

educ_effec $=1.103+0.761 \cdot$ area_room +0.292 . distance_cent $+0.785 \cdot$ number_teachers +0.299 . masters_degree $+0.189 \cdot$ conference_pupils +0.278 . learning_foreign language $+0.892 \cdot$ teachers_us in innovation website $+0,115 \cdot$ training_qualific

Parameters calculated using computable and random effects models appear to differ slightly from those calculated using the least square method. First, most of the independent variables are almost identical.

Table 2

Results of the Housman test

\begin{tabular}{|c|c|c|c|c|}
\hline & \multicolumn{4}{|c|}{ Coefficients } \\
\hline & fixed & random & difference & standart error \\
\hline area_room & 0,62345 & 0,54872 & 0,07473 & 0,78156 \\
\hline distance_center & 0,72589 & 0,01256 & 0,71333 & 0,40458 \\
\hline number_teachers & 0,25421 & 0,01572 & 0,23849 & 0,04587 \\
\hline masters_degree & 0,34587 & 0,23546 & 0,11041 & 0,21457 \\
\hline conference_pupils & 0,74561 & 0,87426 & $-0,12865$ & 0,42156 \\
\hline $\begin{array}{l}\text { learning_foreign } \\
\text { language }\end{array}$ & 0,04578 & 0,36017 & $-0,31439$ & 0,89745 \\
\hline $\begin{array}{l}\text { teachers_using } \\
\text { innovation website }\end{array}$ & 0,05687 & 0,24587 & $-0,189$ & 0,74215 \\
\hline training_qualific & 0,78574 & 0,8324 & 0,1152 & 0,2631 \\
\hline $\mathrm{B}=$ & \multicolumn{4}{|c|}{$\begin{array}{l}\mathrm{b}=\text { consistent under Ho and Ha; obtained from xtreg } \\
\text { in consistent under Ha, efficient under Ho; obtained from } \mathrm{x} \text { treg }\end{array}$} \\
\hline Test : $\mathrm{H}_{0}$ & \multicolumn{4}{|c|}{$\begin{array}{l}\text { difference in coefficients not systematic } \\
\text { chi2 }(7)=(b-B)^{\prime}\left[\left(V_{-} \_-V_{-} \_B\right)^{\wedge}(-1)\right](b-B) \\
8.26 \\
\text { Prob }>\text { chi } 2=0.8134\end{array}$} \\
\hline
\end{tabular}

In addition, the parameters with unexpected gains in accordance with the learning efficiency calculated by the least square method are the expected parameters in panel models. That is, the parameters calculated as a result of taking into account the heterogeneity of the schools, remain valid. Second, the calculated parameters in the invariant and random effects models show a close elasticity. In other words, it can be seen that the parameters calculated using the least square method are almost the same distance from the quantitative point of view.

Consequently, in the fixed effects model: area_room, distance_center, number_teachers, masters_degree, conference_pupils, training_qualific, and teacher_using innovation website, the effectiveness of education depends on these factors and 0.734 respectively; $0.034 ; 0.789 ; 0.331$;
$0.232 ; 0.464 ; 0.064$ also in the random effects model: $0.761 ; 0.292 ; 0.785 ; 0.299 ; 0.189 ; 0.278$; Causing an increase of 0.892 percent.

Which of these two panel models best explains the effectiveness of schooling is explained by several criteria $(\operatorname{cov}(\varepsilon i t, 0)=0$. Although these are statistically significant depending on the individual statistical significance of the parameters, the general significance test (F test, $\chi 2$ test)) a formal Hausman test was applied. 


\section{DISCUSSION}

Current research on school education quality through the guiding innovative principles can be example for all schools of the Bukhara region. Development education quality program of each schools recommended testing five parameters for raising visibility among schools as follows:

Number of master degree teachers at school

- Attendance of pupils at conferences and workshops

- Foreign language proficiency

- Regularly using website of the Ministry of Innovation Uzbekistan

- Participation at trainings and achievements of teacher's qualification

Following figures illustrate the individual impact of selected factor which is studied on education_efficiency. Each factor included in the model is selected based on the above-mentioned parameters and extent effectiveness of education at schools. In addition some other factors influencing into model are very high but they are not included in the model. However, as a result of modeling other factors influencing factors significantly reduced the affect of the factors related other trends. Aftermath education_efficiency was performed and depicted in individual figures as below (Fig. 1,2,3,4,5). As for the system effectiveness acquired factors which have been given better results remained in the model.

Figure 1

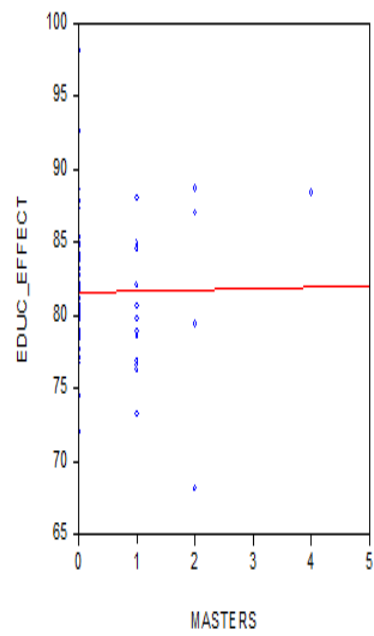

Figure 3

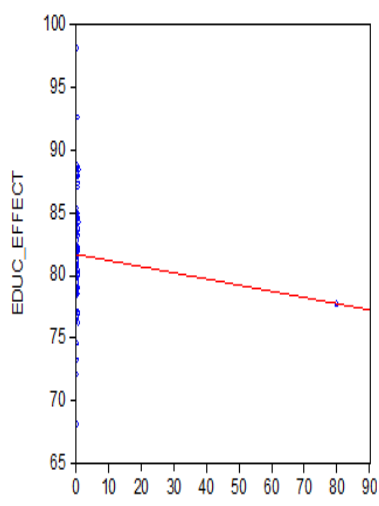

LIERACYOFFOREIGNLANG_TEA
Figure 2

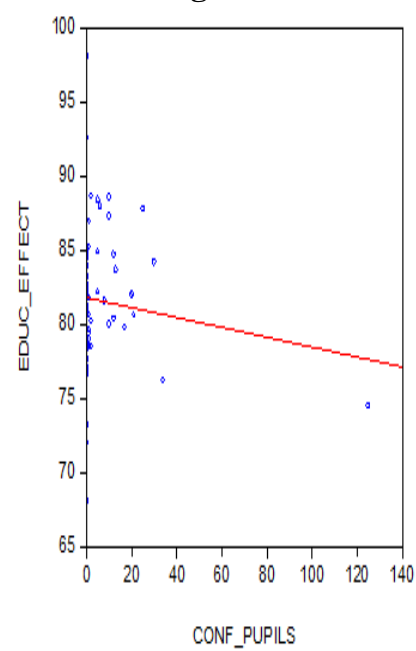

Figure 4

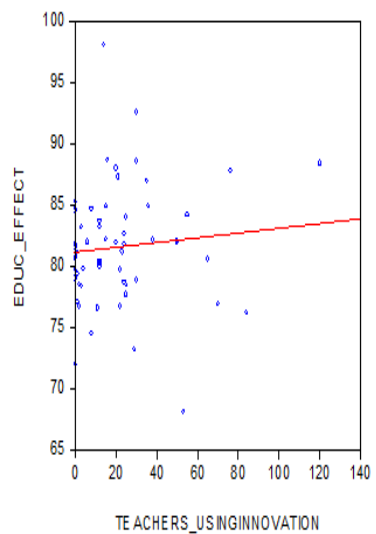

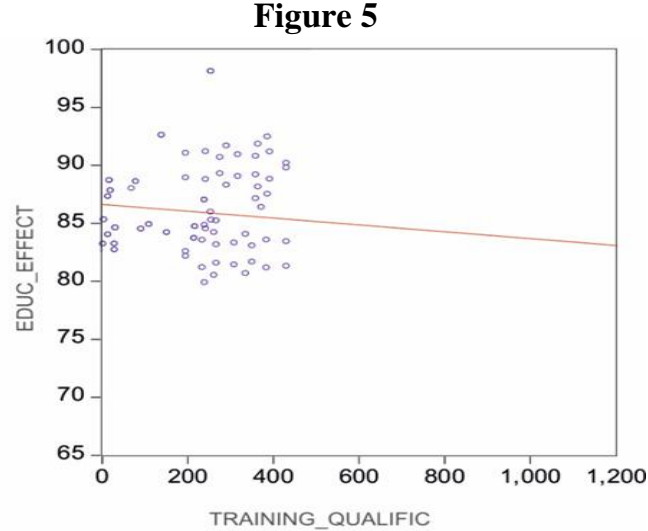

Authors describe a broad approach to improve school quality systems should strive for. This is expressed in the following concepts:

Firstly, if we increase number of master degree teachers at school secondary education quality will improve 0,799 coefficient. Because teachers with such a skills and experience have enough theoretical and practical approach of their field. And master's teachers mainly have special ability on problem solving in scientifically. They have approved ability on making research and put forward hypothesis various point of views.

Secondly, attendance of pupils at local or international conferences and participation of scientific or technical workshops will provide new vision and methods on improvement of decision making and self-confidence at classes. Especially, meeting with a new auditory and friends can help development of cross-cultural relations among pupils. For whom would like to improve personal development skills and professional development careers conferences, workshops, and seminars are best way.

Thirdly, foreign language proficiency is the main parameter in education system. Foreign experience and innovations in science and technology are mainly discovered, explored in advanced economies like G-20 and E-7 countries in the past. Globalization of education all over the world can be widespread or transmitted in perhaps particular world languages. For collecting facts, innovative techniques and learning methodology in education are easier for understanding, collecting, analyzing, interpreting and reporting of information. Schools leaders and teachers need opportunities to take considered new perspectives in order to innovate and develop local education quality in internationally.

Fourth, implementing innovations in each subject can be advantage or priority of teacher and pupils too. They are more confident of achievements what they are teaching, learning, understanding and current results. World class secondary education system news, results and outcomes are provided on this website. Studying World Bank, UNESCO, UNICEF, OECD, UNDP and other international organization annual reports on education and how organize learning subjects, leadership, classroom managements skills and so on. Announcing scholarships and grants by the 


\section{IMPROVING THE SCHOOL QUALITY THROUGH WINNING EDUCATION TURBULENCE IN UZBEKISTAN (EVIDENCE FROM THE MINISTRY OF SECONDARY EDUCATION UZBEKISTAN, GIJDUVAN REGION 65 SCHOOLS)}

ministry provides competitive education among pupils which serve for the school quality in regions.

Fifth, participation at advanced trainings of teacher can help learning modern tendencies of how to teach pupils effectively. Perhaps, it has been proven instant of teacher centered method into student centered more accurate with interactive ways of improving interest area of the pupils at classes. Training and Qualification Center in secondary education system of Uzbekistan by name Abdulla Avloniy targeted approved high qualified and skills in all area of secondary school directors. Currently modern innovative methodology of effective teaching and learning management, leadership curriculum and syllabus are upgrading in terms of international cooperation with US, UK, Japan, Korea, Russia etc.

During teaching and learning process at school education quality is all time changes dynamically. It is mainly because of teacher or pupils' factors at classes. As for the experience of Finland that number of master level teachers effect positive effectiveness at secondary education quality. Personal development, creativity, self-confidence and problem-solving skills can be acquired definitely at workshops etc. Yellow area is a low effective school quality in teaching, leadership and innovation (Fig 6). If we implement five parameters in other schools will be able improve quality education by developing teachers and pupil's ability in secondary education in Gijduvan. This is only way winning loses of time, money and prospective dreams of pupils.

Figure 6 Winning turbulence education

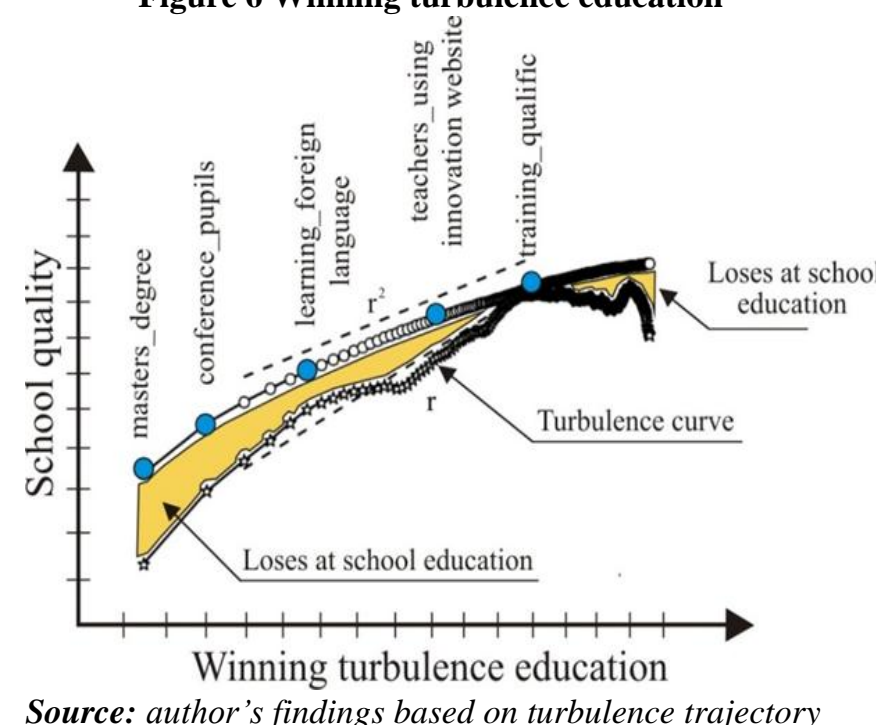

Source: author's findings based on turbulence trajectory

Figure 7

Winning turbulence education with innovation mode

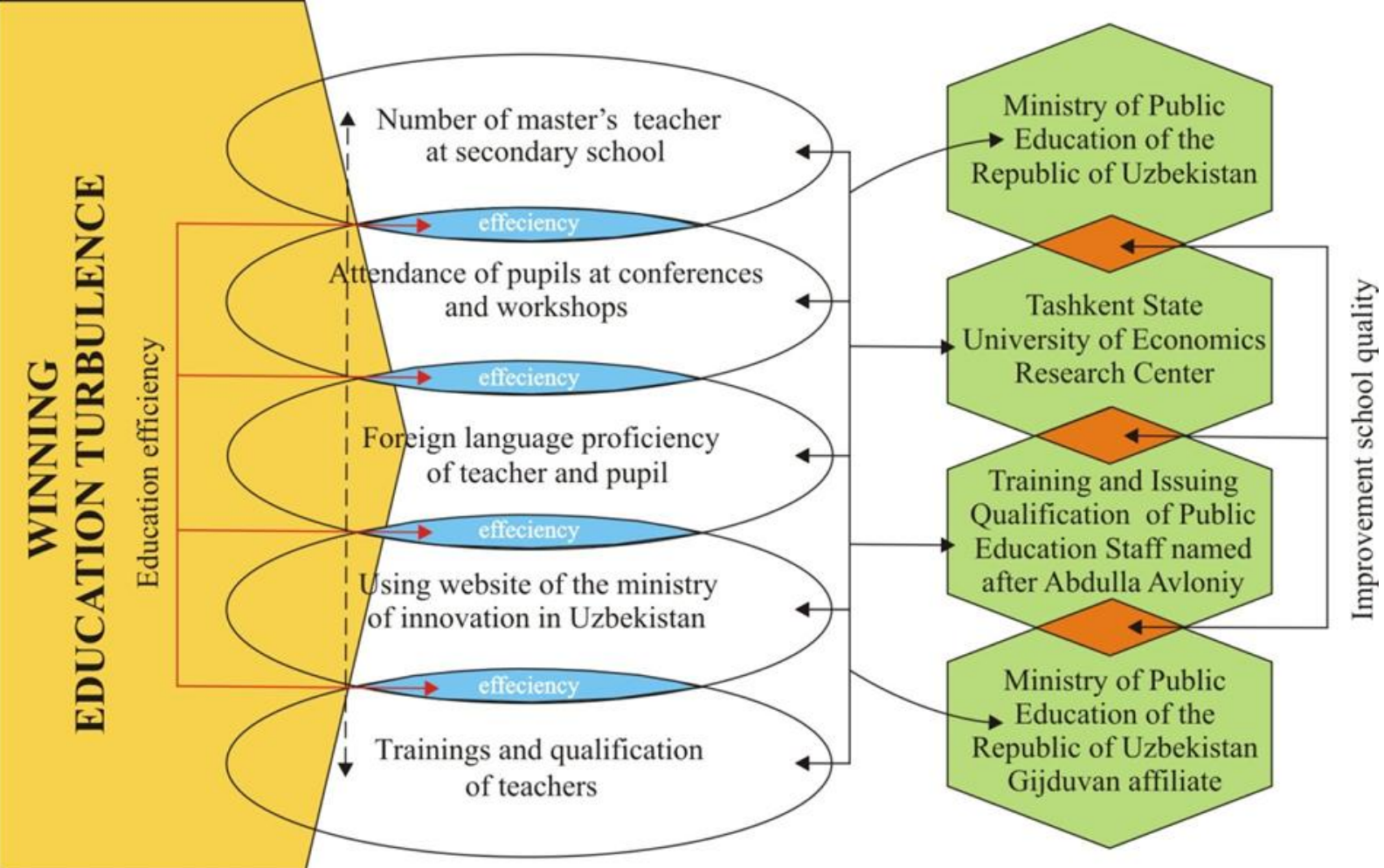

Source: author's findings

Current model presents clear clarification main outcomes form the research. This is conceptual relationship between selected variables and prospective improvement of education quality. Cross sectional area is calculated efficiency at schools in particular period of time. The next four institution are can be analyzed as future improvement school quality while true application of final outcomes and implementing fixed effects model (Fig. 7). Expected result can be achieved while direct relationship of secondary education with science and business. 


\section{CONCLUSION}

On brief analysis of the situation in secondary education in Gijduvan district, Bukhara region authors would like to offer the following school performance parameters that could be taken into account by the government to deal with improving school quality and try to winning turbulence education in Uzbekistan. Due to the same instruction and requirements have been issued in the same level for all public schools of Uzbekistan research results can applicable in other regions too. Analyses showed that three parameters are also influenced improving school quality but significance is less than 10 percent. School leaders, principals must play a key role in setting direction and creating a positive school quality including the proactive school visibility. Supporting and enhancing motivation commitment needed to foster improvement and promote success for all schools in challenging circumstances in future. Authors believe in cooperation of Ministry of Public Education with TSUE Research Center for improving quality education at schools scientifically and practically with empirical analyses in Uzbekistan.

\section{ACKNOWLEDGMENT}

The authors' grateful thanks go to all 65 school directors of Gijduvan for supporting data collection in this matter. For best contribution the authors honored scholars and academic advisors who also helped with their idea, recommendation and instruction at this research.

\section{REFERENCES}

1. Angrist, J.D., Lavy, V., 1999.Using Maimonides' rule to estimate the effect of class size on scholastic achievement. Q. J. Econ. 114, 533-575.

2. Australian Principals Associations Professional Development Office (APAPDC) (2000).

3. Chetty, R., Friedman, J.N., Rockoff, J.E., 2014.Measuring the impacts of teachers I: Evaluating bias in teacher value-added estimates. Am. Econ. Rev. 104 (9), 2593-2632.

4. Christopher Day and Pamela Sammon, Successful school leadership, 1999, p48.

5. Clark, D., 2010.Selective schools and academic achievement. BE J. Econ. Anal. Policy 10 (1935-1682).

6. Coleman, J.S., Campbell, E.Q., Hobson, C.J., Mc. Partland, J., Mood, A.M., Weinfeld, F.D., York, R.L., 1966.Equality of Educational Opportunity. U.S. Government Printing Office, Washington, D.C.

7. Cullen, J.B., Jacob, B.A., Levitt, S.D., 2005.The impact of school choice on student outcomes: an analysis of the Chicago public schools. J. Public Econ. 89 (5),

8. Currie, J., Thomas, D., 1999.Early Test Scores, Socioeconomic Status, and Future Out-comes. NBER Working Paper No. 6943.

9. Dynarski, S., Hyman, J.M., Schanzenbach, D.W., 2013.Experimental evidence on the effect of childhood investments on postsecondary attainment and degree completion.

10. European ideas for better learning: the governance of school education systems Produced by the ET 2020 Working Group Schools The final report and thematic outputs of the ET2020 Working Group Schools, 2018, p 4.

11. Goldhaber, D.D., Brewer, D.J., 2000.Does teacher certification matter? High school teacher certification status and student achievement. Educ. Eval. Policy Anal. 22 (2), 129-145.

12. Hanushek, E.A., Rivkin, S., 2006.Teacher Quality. In: Hanushek, E., Welch, F. (Eds.), Hand-book of the Economics of Education Volume 2. Elsevier North Holland, Oxford, pp. 1051-1078.

13. Hastings, J.S., Weinstein, J.M., 2007.No Child Left Behind: Estimating the Impact on Choices and Student Outcomes. NBER Working Paper No. 13009.

14. Jackson, C. Kirabo, 2013.Match quality, worker productivity, and worker mobility: Direct evidence from teachers. Rev. Econ. Stat. 95 (4), 1096-1116.

15. Pop-Eleches, C., Urquiola, M., 2013.Going to a better school: Effects and behavioral responses. Am. Econ. Rev. 103 (4), 1289-1324.

16. Quality assurance for school development Guiding principles for policy development on quality assurance in school education Produced by the ET 2020 Working Groups, EUROPEAN COMMISSION, 2017, p3.

17. Rivkin, Steven G., Hanushek, Eric A., Kain, John F., 2005.Teachers, schools and academic achievement. Econometrica 73 (2), 417-458.

18. Rockoff, Jonah E., 2004.The impact of individual teachers on student achievement: Evidence from panel data. Am. Econ. Rev. 94 (2), 247-252

19. Rockoff, Jonah E., Jacob, Brian A., Kane, Thomas J., Staiger, Douglas O., 2011.Can you recognize an effective teacher when you recruit one? Education. Finance. Policy $6(1), 43-74$.

20. Successful school leadership, copyright education development trust 2016. the views and opinions expressed in this publication are those of the authors and do not necessarily represent the views of education development trust, 2014 report 978-1-909437-76-0, p7. 